\title{
Fatigue characteristics of welded high strength steel in the low cycle region of loading
}

\author{
Peter Kopas ${ }^{1,}{ }^{*}$, Milan Sága ${ }^{1}$, Marián Handrik ${ }^{1}$, Milan Vaško $^{1}$, and Lenka Jakubovičová ${ }^{1}$ \\ ${ }^{1}$ University of Zilina, Faculty of Mechanical Engineering, Department of Applied Mechanics, \\ Univerzitná 1, 010 26, Zilina, Slovak Republic
}

\begin{abstract}
Automotive industry is the one of the most rapidly developing sector of engineering. Using of new, progressive materials can make significant benefits because of growing durability and reducing weight of structural parts, which can lead to the materials and fuel savings. The authors of this paper discuss fatigue characteristics on arc metal welding process of high strength steels STRENX 700MC obtained in low cycle region $(\mathrm{N}$ approximate to $1.10(3)$ divided by $N=1.10(7)$ cycles) at low-frequency loading (frequency approximate to $35 \mathrm{~Hz}, \mathrm{~T}=20+/-5$ degrees $\mathrm{C}, R=-1$ ). Authors compares results of their own experimental works and subsequently discus these result and their possible effect on the fatigue lifetime of these steels.
\end{abstract}

Keywords: low-cycle fatigue, arc welding, high-strength steel

\section{Introduction}

Over the last years a strong interest has been expressed to produce lighter structures. One possible solution to reduce the weight is to utilize high strength steels significantly more than today and use welding as the joining method. Welding is the main joining method for fabrication of a large proportion of all engineering structures. Many components experience fatigue loading during all or part of their life time and welded connections are often the prime location of fatigue failure $[1,2]$. This becomes more critical in welded high strength steels as fatigue strength of welds does not increase by increasing the steel strength. A possible solution to overcome this issue is to use fatigue improvement methods. The two main approaches are: modification of the weld toe geometry and modification of the residual stress induced by welding (for example by shot peening) [3]. The former improves the fatigue strength through reduction of the local stress concentration factor by ensuring a smooth transition between the weld profile and base metal. The latter contributes to fatigue strength increase by reducing tensile residual stresses or even by inducing compressive residual stresses in the weld toe region [4-6].

The most difficult aspect of fatigue is to detect the progressive changes in material properties that occur during cyclic stressing and the failure may therefore occur with no

\footnotetext{
* Corresponding author: peter.kopas@,fstroj.uniza.sk

Reviewers: Ireneusz Malujda, Františka Pešlová
} 
apparent warning. Also, periods of rest, with the fatigue stress removed, do not lead to any measurable healing or recovery from the effects of the prior cyclic stressing. Thus the damage done during the fatigue process is cumulative and generally unrecoverable [5]. Fatigue failure is an extremely complex physical process which is governed by a great number of parameters related to, for example, local geometry and material properties of the structural region surrounding the crack growth path. It is commonly recognized that it is impossible for a physical model to account for all fatigue influencing parameters, thus a lot of approximate models have been conceived for practical fatigue assessments. In every stadium of fatigue cumulative damage dominates a definite mechanism controlled by more or less known and verified rules [7-9]. Fatigue is the process by which a crack can form and then grow until final failure of the component, under repeated loading [1, 10]. According to the American Society for Testing and Materials (ASTM), Standard E 1823 [11] fatigue is defined as: " the process of progressive localized permanent structural change occurring in a material subjected to conditions that produce fluctuating stresses and strains at some point or points and that may culminate in cracks or complete fracture after a sufficient number of fluctuations". Fatigue is the cause of about $90 \%$ of engineering component failures [10]. The process of fatigue fracture is usually divided into three phases:

- crack initiation or nucleation,

- crack growth,

- final fracture.

Cracks often initiate along slip lines oriented in the planes of maximum shear stress. Cracks can also initiate at or near material discontinuities such as inclusions, grain boundaries, pores and voids. Phase of crack growth has two stages itself. The two stages of fatigue crack growth are called "stage I" (shear mode) and "stage II" (tensile mode). During the first stage of crack growth, a crack initiated from the surface and grows within a few grains primarily controlled by shear stresses and strains. When the crack reaches over several grains, it will continue to grow in a direction perpendicular to the largest tensile principal stress. The final fracture will take place when the crack becomes so large that the remaining part of the cross section is too small to with stand the load and subsequently complete fracture happens [12-14].

To properly perform such laboratory tests, the local cyclic stress-strain history at the critical point in the structure must be determined, either by analytical or experimental means. Thus valid stress analysis procedures, finite element modelling or experimental strain measurements are necessary, and the ability to properly account for plastic behaviour must be included. In performing smooth specimen tests of this type, it must be recognized that the phenomena of cyclic hardening, cyclic softening and cycle-dependent stress relaxation, as well as sequential loading effects and residual stress effects that may be experienced by the specimen as it accumulates fatigue damage are presumed to be the same as at the critical point of the structure member being simulated. Since, including all these factors in a test is inconvenient, inaccurate and expensive, the use of finite element method has become a powerful tool to calculate the cyclic stress-strain response of any structure or mechanical component. The finite element method is especially used in the ground vehicle industry where discontinuities of the geometry such as notches and holes produce difficulties to calculate the local cyclic stresses and strains, which are essential to predict the fatigue life of any structure or component [15, 17-22].

Fatigue failure is considered to be a main factor which limits the design stresses for components subjected to repeated loading. This is particularly important for welded components because fatigue strength of welded structures are much lower than those of unwelded components. The strength analysis of welded structures does not deviate much from that for other types of structures. Various failure mechanisms have to be avoided through appropriate design, choice of material, and structural dimensions. Design criteria such as yielding, buckling, creep, corrosion, and fatigue must be carefully checked for specific 
loading conditions and environments. Fatigue cracks may initiate and grow in the vicinity of the welds during service life even if the dynamic stresses are modest and well below the yield limit [9]. However, the fatigue strength of a welded joint is not primarily governed by the strength of the base material of the joining members; the governing parameters are mainly the global and local geometry of the joint. Hence, the yield stress is increased, but the fatigue strength does not improve significantly. As already stated, the fatigue behaviour of welded joints is random by nature. Furthermore, the in-services stresses may often be characterized as stochastic processes $[1,6]$. However, a welded joint has some peculiar features that make some of the subjects and parameters play a much more important role than others $[3,10]$.

\section{Test equipment design}

The design of experimental equipment is based on a mechanical principle. The constant rotation is generated by excenter and linkage mechanism. By changing of eccentric magnitude it is possible to change a loading magnitude. Also if we change the length of connecting crank on the experimental equipment, there will be a change in the loading cycle character (proportional-non-proportional loading, bending/torsion loading, etc.). Power of the device is secured by two synchronic electro motors with frequency converters from $0.5 \mathrm{~Hz}$ to $100 \mathrm{~Hz}$. Loading frequencies are identical with the frequency of rotation drive. Synchronization of the electro motors is secured by electronics and allows synchronization of the loading amplitude. The synchronization of electro motors also allows setting the phase shift for individual loading levels. There are also two force measurement systems included in the experimental equipment. These systems may be used for measurement of force values during the loading process. For evaluation of fatigue curves it is necessary to know stress and strain conditions on individual loading levels.

\section{Experimental material and strain-life data results}

Seventeen smooth specimens were tested under strain controlled conditions in order to identify the strain-life behaviour of the arc welded Domex $700 \mathrm{MC}$ and electron beam welded Weldox 960 high strength steels. After machining, the specimen surfaces were mechanically polished. The experiments were carried out in an electro mechanic fatigue test machine, developed on University of Žilina.

For evaluation of fatigue curves it needs to know stress and strain conditions on individual loading levels. A sinusoidal waveform was used as command signal. The fatigue tests were conducted with constant strain amplitudes, at room temperature, in air. The specimens were cyclic loaded under strain control with symmetrical proportional bending loading, with a nominal strain ratio, $R_{\varepsilon}=-1$. The computational fatigue tests were performed under cyclic loading with the zero mean value. Frequency of each analysis was equal to $35 \mathrm{~Hz}$.

Domex cold forming steels are thermo-mechanically rolled in modern plants where the heating, rolling and cooling processes are carefully controlled. The chemical analysis, consisting of low levels of carbon and manganese has precise addition of grain refiners such as niobium, titanium or vanadium. The typical mechanical and chemical composition of our experimental material - high strength streel is shown in Table 1 and Table 2.

Table. 1. Chemical composition of arc welded high strength steel DOMEX $700 \mathrm{MC}$ (weight \%)

\begin{tabular}{|c|c|c|c|c|c|c|c|}
\hline $\mathbf{C}$ & $\mathbf{S i}$ & $\mathbf{M n}$ & $\mathbf{N i}$ & $\mathbf{P}$ & $\mathbf{S}$ & $\mathbf{C r}$ & $\mathbf{M o}$ \\
\hline 0.06 & 0.04 & 1.88 & 0.04 & 0.013 & 0.002 & 0.03 & 0.1 \\
\hline $\mathbf{V}$ & $\mathbf{N}$ & $\mathbf{T i}$ & $\mathbf{C u}$ & $\mathbf{A l}$ & $\mathbf{N b}$ & $\mathrm{B}$ & $\mathrm{C}_{\text {ekv }}$ \\
\hline 0.01 & 0.004 & 0.10 & 0.01 & 0.039 & 0.060 & 0.0001 & 0.41 \\
\hline
\end{tabular}


Table. 2. Mechanical properties of arc welded high strength steel DOMEX 700 MC

\begin{tabular}{|l|c|}
\hline Ultimate tensile strength & $705 \mathrm{MPa}$ \\
\hline Tensile yield strength & $620 \mathrm{MPa}$ \\
\hline Elongation at fracture & $7 \%$ \\
\hline
\end{tabular}

Weldox is an SSAB construction steel for general use with a minimum sliding range of 850 to $960 \mathrm{MPa}$ depending on thickness. Typical applications are load-bearing structures with high light weight requirements. The typical mechanical and chemical composition of our experimental material - high strength streel is shown in Table 3 and Table 4.

Table. 3. Chemical composition of electron beam welded steel WELDOX 960 (weight \%)

\begin{tabular}{|c|c|c|c|c|c|c|c|}
\hline $\mathbf{C}$ & $\mathbf{S i}$ & $\mathbf{M n}$ & $\mathbf{N i}$ & $\mathbf{P}$ & $\mathbf{S}$ & $\mathbf{C r}$ & $\mathbf{M o}$ \\
\hline 0.14 & 0.29 & 1.14 & 0.05 & 0.006 & 0.003 & 0.30 & 0.17 \\
\hline $\mathbf{V}$ & $\mathbf{N}$ & $\mathbf{T i}$ & $\mathbf{C u}$ & $\mathbf{A l}$ & $\mathbf{N b}$ & $\mathbf{B}$ & Cekv \\
\hline 0.015 & 0.003 & 0.007 & 0.01 & 0.035 & 0.004 & 0.001 & 0.43 \\
\hline
\end{tabular}

Table. 4. Mechanical properties of electron beam welded high strength steel WELDOX 960

\begin{tabular}{|l|c|}
\hline Ultimate tensile strength & $1096 \mathrm{MPa}$ \\
\hline Tensile yield strength & $1055 \mathrm{MPa}$ \\
\hline Elongation at fracture & $7 \%$ \\
\hline
\end{tabular}

Both experimental material used in this research was delivered in the form of a cylindrical shape with a diameter $10 \mathrm{~mm}$. The length of cylindrical bars was $150 \mathrm{~mm}$.

The test bars were sequentially tested at different load levels, with the computer program recording the number of cycles to the refraction. From experimentally measured values of number of cycles to failure was created uniaxial fatigue curve, which is shown in Fig.1. For fatigue test interpretation on each loading levels it is necessary to know the plastic strain amplitude (Manson-Coffin curve) or stress amplitude (Wöhler curve) applied on each cycle loading level. For that it is necessary to analyze the stress and strain maximum values by FEM that were applied on experimental fatigue equipment. 


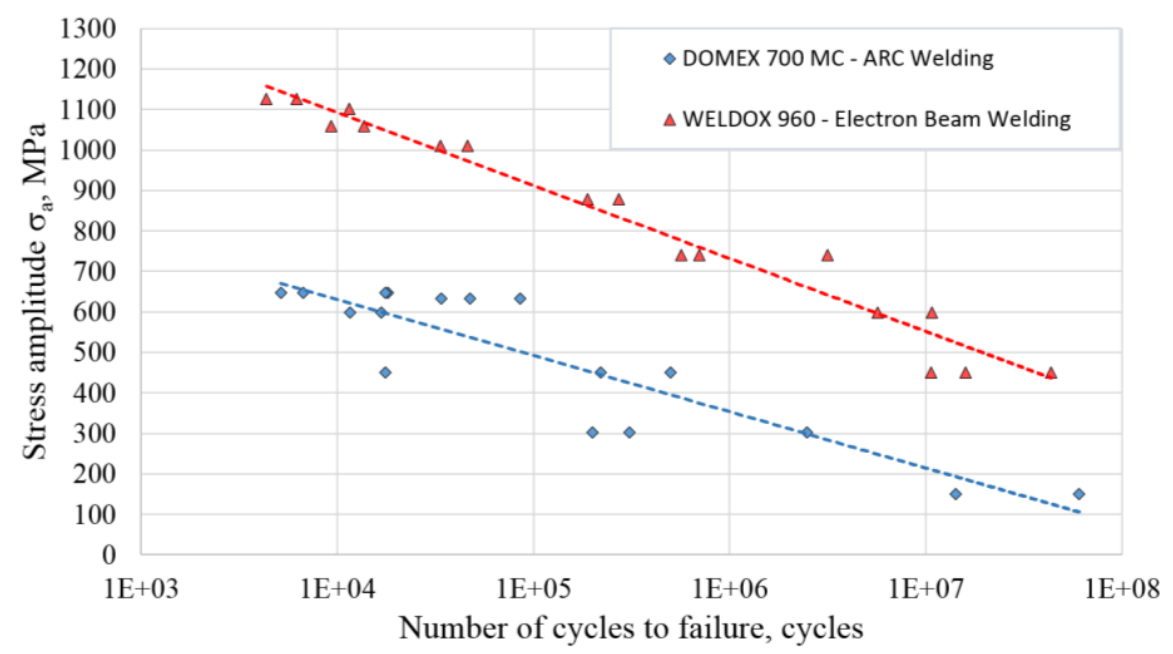

Fig. 1. S-N curves for welded high strength steel DOMEX 700 MC and WELDOX 960

The specimen model was created by the finite-element program ADINA. The material was assumed plastic-bilinear; the true stresses were obtained from a real stress-strain graph. The tetrahedron linear element type was automatically generated. The "Load Plot" function was defined by eccenter setting with eccentricity $2 \mathrm{~mm}$. At the fix point shell and beam elements were used for hammer simulating. From the computational analysis can be seen that the area with the greatest concentration of stresses or the place with the higher deformation was localized in the middle of the rod radius, see Fig 2.

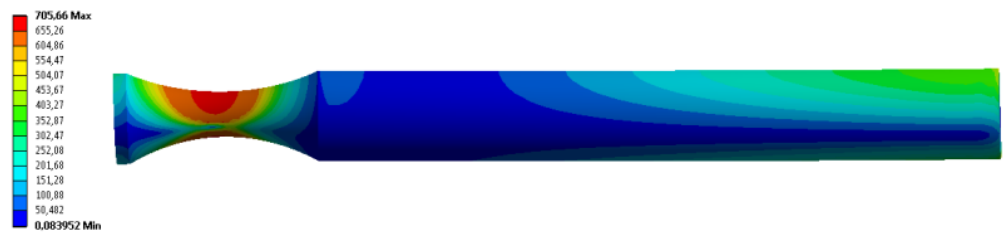

Fig. 2. Result of FEM analysis

\section{Conclusion}

In this study, the low-cycle fatigue behaviour of welded high-strength steel Domex $700 \mathrm{MC}$ and Weldox 960 smooth bars was experimentally evaluated. Tests were performed under strain controlled conditions bending loading on machined bar specimens by means of a simple loading apparatus that allowed to reach high strain levels. On the basis of the tests performed, the following conclusions were formulated:

- The fatigue resistance of both experimental materials increases with decreasing stress amplitude continuously in the cycles of number region.

- The mechanical properties of DOMEX 700 MC welded by the MAG method are lower compared to the base material and the laser-welded material, which is consistent with the findings of other authors.

- For the Weldox 960 experimental material, the electron beam welding in mechanical properties did not significantly increase compared to the non-welded material. The test rod for the static test broke out of the welding joint area and the measured tensile yield strength exceeded the minimum required value $R_{e \min }=960 \mathrm{MPa}$ for the base material. 
- Both experimentally verified materials account reduced ductility beside guaranteed values for non-welded material. In the case of arc welding for Domex $700 \mathrm{MC}$, the phenomenon is closely related to the change of strength properties and fracture in the heat-affected zone (HAZ) affected by the microstructure. In the case of electron beam welding for Weldox 960, the test bars for the static test were broken out of the weld area. The decrease of ductility that is associated with it can be interpreted as the effect of the quality of the welded joint formed with the very narrow area of heat-affected zone. This was reflected in the static as well as dynamically verified parameters of this material.

Residual stress is an important factor influencing the structural behaviour in all instability failures as well as in fatigue crack initiation and propagation when cyclic service stresses are superposed onto the residual stresses. The presence of residual stresses in engineering components and structures can significantly affect the fatigue behaviour during external cyclic loading. The existence of tensile residual stresses in a surface layer accelerates crack initiation reducing fatigue life due to the increase of local mean stress.

This work was supported by the Slovak Research and Development Agency under the contract No. APVV-14-0096.

\section{References}

1. S. J. Maddox, Fatigue strength of welded structures. (Second Edition, Woodhead Publishing, UK, 1991)

2. A. Hobbacher, Recommendations for fatigue design of welded joints and components. (International Institute of Welding, 2004)

3. R. Ulewicz, P. Szataniak, F. Nový, L. Trško, O. Bokůvka, Fatigue characteristics of structural steels in the gigacycle region of loading. Materials Today-Proceedings, $\mathbf{4}$, Issue 5, 5979-5984 (2017)

4. G. B. Marquis, Durability of advanced fabricated structures. (Mater Werkst, 2011)

5. E. Kalentev, Š. Václav, P. Božek, A. I. Korshunov, V. Tarasov, Numerical analysis of the stress-strain state of a rope strand with linear contact under tension and torsion loading conditions. In Advances in Science and Technology Research Journal, 11, Issue 2, 231-239 (2017)

6. P.J.E. Forsyth, The Physical Basis of Metal Fatigue. (Blackie and Son, London, 1969)

7. J. Lago, M. Guagliano, F. Nový, O. Bokůvka, Influence of laser shock peening surface treatment on fatigue endurance of welded joints from S355 structural steel. Manufacturing technology, 16, Issue 1, 154-159 (2013)

8. M. Kubiak, T. Domanski, V. Dekýš, A. Sapietová, Measurement of strain during tension test of welded joint using multi-camera $3 D$ correlation system. XXI Polish-Slovak Scientific conference machine modeling and simulations MMS 2016, Procedia Engineering, 177, 107-113 (2017)

9. W. Piekarska, M. Kubiak, M. Žmindák, Issues in numerical modeling of phase transformations in welded joint. XXI Polish-Slovak Scientific conference machine modeling and simulations MMS 2016, Procedia Engineering, 177, 141-148 (2017)

10. K. Mcdonald, Fracture and fatigue of welded joints and structures. (Elsevier, 2011)

11. ASTM E1823-96 (2002), Standard Terminology Relating to Fatigue and Fracture Testing. (ASTM International, West Conshohocken, PA, 2002)

12. N. E. Dowling, Mechanical behavior of materials: engineering methods for deformation, fracture and fatigue. (Prentice Hall, 1993) 
13. S. Suresh, Fatigue of materials. (Cambridge university press, 1998)

14. R. I. Stephens, A. Fatemi, R. R. Stephens, H. O. Fuchs, Metal fatigue in engineering. (JohnWilley \& Sons, NY, 2001)

15. P. Kováčiková, R. Bezdedová, J. Jr.Vavro, J. Vavro, Comparison of numerical analysis of stress-strain states of cast iron with vermicular graphite shape and globular graphite shape. 20 th International conference machine modeling and simulations MMS 2015, Procedia Engineering, 136, 28-32 (2016)

16. R. Grega, J. Krajnak, L. Zul'ova, G. Fedorko, V. Molnar, Failure analysis of driveshaft of truck body caused by vibrations. Engineering Failure Analysis, 79, 208-215 (2017)

17. J. Szweda, Z. Poruba, R. Sikora, J. Podešva, Computational Analysis of Mechanism Operability. Applied Mechanics and Materials, 315, 879-883 (2013)

18. V.P. Mateichyk, V.P. Volkov, P.B. Komov, I.V. Gritsuk, et al. Special features of vehicle condition monitoring using onboard diagnostics systems. Project management, systems analysis and logistics, scientific journal, NTU, 13, 126-138 (2014)

19. Y. Turygin, P. Božek, I. Abramov, N. Vasilievič, R. Yury, Reliability determination and diagnostics of a mechatronic system. In: Advances in Science and Technology Research Journal, 12, Issue 2, 274-290 (2018)

20. P. Krawiec, Numerical Analysis of Geometrical Characteristics of Machine Elements Obtained Through CMM Scanning. Progress in Industrial Mathematics, SpringerVerlag, Berlin-Heidelberg, 925-930 (2010)

21. M. Macko, J. Flizikowski, The method of the selection of comminution design for nonbrittle materials. Conference Proceedings AIChE, Comminution - Experiments, Theory \& Modeling, 11 (2010)

22. J. Gerlici, T. Lack, Rail vehicles brake components test bench utilisation. Applied Mechanics and Materials, 486, 379-386 (2014) 